vidual movements, but they do wave the first pair of legs when disturbed. If a host comes within reach they are able to get on.

Mr. BraIN: In connection with this point I might mention that in the case of Argas persicus Oken, the sense of smell seems to be depended upon almost entirely in finding a host. Temperature probably plays a slight part too, but I found by experiment that if the first pair of legs are amputated the ticks live quite well for a time, but apparently die later of starvation. A number of such ticks were placed, together with normal specimens, in a box containing a chicken. Next morning it was found that 27 out of 30 of the normal ticks had fed while only 1 out of 30 of the specimens without the front pair of legs was engorged.

President W. D. Hunter: In that case are the legs not used for grasping?

Mr. Brain: I think not. The ticks use them most for touch. The front pair are not used for grasping.

Mr. E. C. Cotron: In regard to Mr. Hunter's question I think that Dr. Nuttall, of the University of Cambridge, has demonstrated very nicely that ticks are dependent upon the Haller's organ for the location of their host. This organ which is olfactory in function, and the only sense organ that has been clearly demonstrated in ticks, is situated on the last tarsal segment of the first pair of legs. With ticks of four different species, which in nature feed only upon blood, he was able, by amputating this segment, thus removing the sense of smell, to induce them to engorge on various liquids some of which caused the death of the tick.

President W. D. Hunter: If there is no further discussion we will proceed to the next paper by Mr. S. J. Hunter, on "Pellagra and the Sand-fly."

\title{
PELLAGRA AND THE SAND-FLY, II
}

By S. J. Honter, University of Kansas, Lawrence, Kans.

At the Washington meeting last year an account of this work up to that time was given, in which 1,282 live sand-flies were used in an endeavor to produce experimentally Pellagra in guinea pigs and monkeys. The work was resumed at the opening of spring this season and covered three lines of investigations. ${ }^{1}$

1 As last year this work has been carried on with the assistance of Mr. W. T. Emery, one of my graduate students and the pathologic side has been conducted in conjunction with Dean Crumbine and the School of Medicine. 
1. The survey on the distribution of sand-flies in Kansas.

2. A detailed investigation into their life habits and conditions under which they exist.

3. Continuation of the inoculation experiments.

Since these investigations when completed will be published in full it is not the purpose of this"paper to occupy your time now with details, but rather to give in briefest possible form a summary of the work thus far, under the above heads.

I-Distributon: The only species thus far found to be generally distributed over the state is Simulium vittatum. The survey thus far seems to show that the immature forms of this species may be found where ever there is trickling water, throughout the summer months. I use the word trickling in order to include watérs which flow from running springs, in little rivulets through the grass. Here attached to the blades of such grass Simulium larvæ sometimes abound.

II-Life History: This species is not confined to clear or pure water. A short distance below where the septic tank of a city of the second class empties into the Neosho, larvæ and pupæ were abundant this season.

In an examination of the riffles for a considerable distance along the bed of a small creek, the only place these larvæ were found was in the riffles running through a hog lot. There the hogs were wallowing and polluting the waters in and above the riffles.

They are not confined to the rural districts but are found in Turkey Creek which runs through a populous part of Kansas City. Last season they were more abundant here than elsewhere.

The females prefer to oviposit in the evening and place their eggs on wet leaves in shallow ripples or on rocks in the same position. They usually place the tip of the abdomen in the water where the water comes up on the rocks in a thin film on the down side of the stream. As the fly oviposits she moves along, stringing the eggs, but holding on to the rock above the water while the tip of the wings and abdomen are vibrating in the water. This process occupies in all about ten minutes and about 200 eggs are usually deposited.

When first deposited the eggs are whitish or creamy in color, turning yellowish, then brownish and almost black at the time of hatching.

When first hatched the larvæ are almost invisible with an ordinary $12 \mathrm{x}$ lens.

The duration of the egg stage depends somewhat upon the temperature of the surrounding water, though usually lasting about a week.

The length of the larval stage depends upon the temperature of the water and upon its rapidity. It varies from three or four weeks 
under good conditions to several months, as this is the overwintering stage.

The duration of the pupal stage varies but is usually two to three weeks.

The length of the adult's life is not definitely known though the flies have been observed to live several days. Those which have fed on human blood exist for a longer period than those which have not. Such have existed eight days before being used. There are two principal broods, one in July and one in October, though some are found emerging throughout the entire season.

As far as our observations go, based on the work of the fly and the anatomy of its mouth-parts these flies do not pierce but rather scrape until the blood oozes through the denuded spot. At certain times they bite the liuman skin readily. A second fly has been observed to participate in lapping up the superabundance of blood caused by the scraping of the first fly.

III-EXPERIMENTS: Last season the flies were very abundant. This season they were notably rare, due principally to the flooded condition of the creeks in the northern part of the state and to the continued drouth in the southern part of the state.

Turkey Creek in the southern part of the state where our breeding experiments were so successful last year was entirely dry this season and the rocks covered with quantities of dried pupæ and larvæ.

It was not possible, therefore, to conduct as many inoculation experiments as last year, due to the absence of flies and likewise to the absence of incipient cases of Pellagra.

Last year we had an abundance of flies and nine cases of Pellagra. This year we had few flies and only two new cases of Pellagra.

Six monkeys were imported direct from India for this work. The almost total absence of flies in July as well as the want of a Pellagrin in the proper stage prevented any successful inoculations then. In the fall brood two inoculations have been made without waiting for the flies to bite the monkey after having bitten the Pellagrin but introducing them by maceration attended by the proper aseptic precautions.

The last inoculation, thus far, was made on a sccond monkey on the dates of December 16, 17 and 20, using flies that had emerged on the 12th and had bitten the Pellagrin on the 14th.

Obviously sufficient time has not elapsed for the results of these experiments to become apparent.

Summing up the work of the past two years, for and against the Sambon theory:- 
1. The number of sand-flies has been directly proportional to the number of cases of Pellagra.

2. The first appearance of the cases of Pellagra is coincident with the principal broods.

3. Just succeeding the time of the principal broods the flies appear to bite more vigorously.

4. Sand-flies which have fed on human blood live several days longer than those which have not been so nourished, thus favoring an incubation period for a parasite if such there be.

5. Pellagra, thus far in Kansas, has appeared almost entirely in one restricted locality. Of the nine cases recorded last year five were traced back to one town. In this region flies are widely distributed and unusually abundant.

Upon the other hand,

1. Pellagra has never been produced in any other animal experimentally either through inoculation or through transference by means of sand-flies.

As far as our history of this subject goes the appearance of Pellagra in Kansas is a recent occurrence. Nearly all of the cases are those of natives that have never been out of the state.

From this it would seem that the etiology of Pellagra exists in Kansas.

The situation here is not complicated through long standing conditions. It is the purpose, therefore, to continue this phase of the work and with it the correlation of the clinical and pathological phases by the medical school of the University of Kansas.

Mr. S. J. Hunter: To illustrate one point: we took this problem up two years ago and reported Douglas County, the county in which the University of Kansas is located, as being absolutely free from Sandfly, and last June I stepped across a stream in the grass which ran about five gallons an hour as an overflow of one of the campus drinking fountains, and found the larvæ there on the blades of the grass in great numbers. That is, it requires an unusual scrutiny of conditions in any given locality before a conclusion can be safely drawn regarding the presence or absence of the Sand-fly.

Piresiden' W. D. Hunter: The reader spoke advisedly when he referred to the Sambon theory. It is surprising that Doctor Sambon has performed no experiments whatever. He has merely drawn conclusions. The work of Mr. Hunter is much more suggestive as regards the demonstration of the possible transmission of pellagra by Sandflies than anything that has been done and allows the suggestion that if the Sambon theory is ever proven it is likely that some other investigator wil! accomplish it. The investigation in South Carolina, which 
the Bureau of Entomology has been conducting in coöperation with the Thompson-McFadden Commission of the New York Postgraduate School of Medicine, has failed to reveal any circumstance that tends to connect Simulium with pellagra transmission. In this work, by means of special facilities provided, an extremely exhaustive investigation of pellagra in a rather restricted locality was conducted. A house to house canvass was carried out and complete accounts of the histories and surroundings of cases were compiled Simulium is present, but not in sufficient numbers and not in the exact places where it would appear possible that they were connected with the disease.

Mr. S. J. Hunter: We talked that over quite fully, Dr. Siler of the Army Medical Corps and I, and both of us spoke of the fact that it was remarkable that a purely geographical theory should receive so much attention. Dr. Siler explains it on the grounds that Sambon seems to be a good prognosticator. For example, Dr. Siler spoke of visiting peasaryt huts with Dr. Sambon, where cattle and people lived under the same roof. Here the stable fly was feeding on both the cattle and peasant. Dr. Sambon remarked to Dr. Siler that there would in all probability be an outbreak of Anthrax here soon. And such an outbreak did shortly occur. One of Sambon's deductions, if frequently corroborated, must certainly be considered as important in its relation to hi; theory. That is, parents and children may all be pellagrins, living in a Sand-fly zone but when the family moves out of the Sand-fly zone subsequent offspring are free from Pellagra.

Mr. W. A. RiLEX: I should like to inquire whether there are any further data relative to the susceptibility to pellagra of the monkeys which are being experimented upon. It is well-known that the typical insect-borne diseases may be transmitted from animal to animal by transfusion of blood as well as by the insect host. This is true of malaria, yellow fever, Texas fever of cattle, and various trypanosome and other diseases. As I recall the report of last year, there was no evidence that the monkeys were affected by transfusion of blood from a pellagrin.

S. J. Honner: That is a question we discussed last year. The monkey has been tried in every shape and form. Transfusions of living blood, inoculation of various organs and tissues taken from recently deceased subjects gave negative results. In this particular, Infantile Paralysis differs in that it was produced experimentally before being carried through the agency of the stable fly.

MR. W. A. RruEY: ' In view of the known difficulty in carrying on experiments regarding the insect transmission of disease, would it not be important to first determine the suceptibility of the animals experimented upon. If the animals are not susceptible of course 
experiments with them to determine whether Simulium transmits pellagra would be futile.

Mr. S. J. HunTer: I may say that the results of the experiments in the laboratory failed to prove that the monkey was susceptíble.

President W. D. Hunter: Is there any further discussion? If not, the next paper is by Mr. C. T. Brues on "The Transmission of Infantile Paralysis by Stomoxys calcitrans."

\section{THE RELATION OF THE STABLE FLY (STOMOXYS CALCIT- RANS) TO THE TRANSMISSION OF INFANTILE PARALYSIS ${ }^{1}$}

\section{A Résumé of Observations by Brues and Sheppard and of Experi- ments by Rosenau and Brues}

By Charles T. Brdes

Infantile paralysis, more accurately designated anterior poliomyelitis or acute epidemic poliomyelitis, is a disease which has aroused much interest in the United States for a number of years on account of its serious nature and much increased prevalence. Complete ignorance as to the way in which it spreads and develops in epidemic form has also scrved to augment the dread of this disease. It affords me great satisfaction, therefore, to be able to present today a résumé of some observations and experiments bearing on the probable method of transmission of infantile paralysis.

These entomological investigations were conducted under the auspices of the Massachusetts State Board of Health and have extended over a period of two years. The State Board had previously conducted extensive investigations along various lines under the guidance of an advisory committee consisting of Drs. R. W. Lovett, M. W. Richardson, M. J. Rosenau, Theobald Smith, J. H. Wright and J. L. Morse, and Doctor Richardson later gave much of his time to further the success of the entomological work. During the summer of 1911 an extended series of entomological field observations was made by the writer in association with Dr. P. A. E. Sheppard who was studying the epidemiology of the disease for the State Board of Health. The more important facts then ascertained have already been published in the Journal of Economic ENTOMOLOGY ${ }^{2}$

\footnotetext{
1 Contributions from the Entomological Laboratory of the Bussey Institution, Harvard University, No. 62.

: Brues, C. T. and Sheppard, P. A. E. The Possible Etiological Relation of Certain Biting Insects to the Spread of Infantile Paralysis. Journ. Econ. Entom. Vol. 5, No. 4, pp. 305-324 (1912), previously briefly abstracted in the Monthly Bulletin of the Mass. State Board of Health for December 1911, pp. 337-340.
} 